\title{
Indução e caracterização morfológica e bioquímica de calos de Hyptis leucocephala (Lamiaceae)
}

\author{
Danilo Marcelo Santos Pereira ${ }^{1}$, Lenaldo Muniz de Oliveira ${ }^{1 *}$, Cristina Ferreira Nepomuceno ${ }^{1}$, José Raniere
} Ferreira de Santana ${ }^{1}$, Marília Lordelo Cardoso Silva² \& Maria Gabriela Bello Koblitz ${ }^{2}$

${ }^{1}$ Departamento de Biologia e ${ }^{2}$ Departamento de Tecnologia. Universidade Estadual de Feira de Santana, Feira de Santana, Av. Transnordestina s.n., Novo Horizonte, 44036-900, Feira de Santana, Bahia, Brasil.

\begin{abstract}
Resumo - Hyptis leucocephala é uma erva aromática endêmica da região semiárida do Brasil, com propriedades antimicrobiana, antifúngica, citotóxica, anti-inflamatória e anti-HIV. O cultivo in vitro possibilitará a produção de mudas com elevada qualidade genética e sanitária para essa espécie, permitindo sua exploração sustentável. Neste trabalho, avaliou-se o efeito da 6-benzilaminopurina (BAP) e do ácido naftalenoacético (ANA) na indução de calos em segmentos foliares desta espécie e de diferentes aditivos orgânicos ao meio de cultura WPM (Wood Plant Medium) na indução de calos. A utilização combinada de BAP e ANA possibilitou a indução de calos compactos e indiferenciados, sendo a maior taxa de calogênese e de crescimento dos calos obtidas com a utilização combinada de 8,88 e 21,48 $\mu \mathrm{M}$ desses reguladores, respectivamente. A suplementação do meio de cultura com água de coco, extrato de malte e extrato de levedura não induziu calos friáveis. Os teores de açúcares totais, açúcares redutores, proteína bruta e aminoácidos livres foram reduzidos nos calos mantidos em meio de cultura suplementado com água de coco, extrato de malte e extrato de levedura. Palavras-chave adicionais: alecrim-do-mato, BAP e ANA, calogênese, MEV, propagação in vitro.
\end{abstract}

\begin{abstract}
Induction and morphological and biochemical characterization of Hyptis leucocephala (Lamiaceae) calluses) - Hyptis leucocephala is an aromatic herb endemic to the Brazilian semiarid region, with antimicrobial, antifungal, cytotoxic, anti-inflammatory and anti-HIV properties. In vitro cultivation makes the production of high genetic and sanitary quality cuttings possible for this species, allowing its sustainable exploitation. In the present study, the effect of 6benzilaminopurine (BAP) and naftalenoacetic acid (NAA) on callus induction in leaf segments of this species and different organic additives to WPM (Wood Plant Medium) for the callus induction was evaluated. The combination of BAP and NAA allowed the induction of compact and undifferentiated calluses. The highest rate of callus formation and growth was obtained with the combination of $8.88 \mu \mathrm{M}$ BAP and $21.48 \mu$ MNAA. Supplementing the culture medium with coconut water, malt extract and yeast extract did not induce friable calluses. The levels of total sugars, reducing sugars, protein, and amino acids were reduced in calluses maintained in culture medium supplemented with coconut water, malt extract and yeast extract.
\end{abstract}

Additional key words: alecrim-do-mato, BAP and NAA, callus induction, in vitro propagation, MEV.

A família Lamiaceae é composta por cerca de 250 gêneros e 6.970 espécies (Judd et al. 1999). Muitas espécies dessa família são endêmicas do Semiárido nordestino, com destaque para o gênero Hyptis Jacq., em virtude da produção de óleos essenciais com ampla atividade biológica. Falcão \& Menezes (2003) citam 25 espécies desse gênero estudadas sob o aspecto farmacológico, descrevendo a presença de substâncias com atividades antimicrobiana, antifúngica, citotóxica, anti-inflamatória, anti-HIV e inseticida.

Hyptis leucocephala Mart. ex Benth. é uma erva aromática decumbente de cerca de $20 \mathrm{~cm}$ de altura, apresenta folhas cartáceas, flores com cálice esverdeado e corola arroxeada, ocorrendo no Semiárido da Bahia. Estudos fitoquímicos têm revelado um rendimento médio de $0,2 \%$ de óleo em suas folhas, com formiato de isobornila como composto majoritário e atividade antimicrobiana frente a Bacillus cereus, Candida albicans e Staphylococcus aureus (Lucchese et al. 2005).

Em virtude do elevado potencial fitoquímico de $H$. leucocephala, torna-se imprescindível o desenvolvimento

"Autor para correspondência: lenaldo@uefs.br

Editora responsável: Raírys Cravo Herrera

Submetido em: 2 maio 2011; publicação eletrônica: 27 junho 2012 de métodos que possibilitem sua exploração econômica de forma sustentável. Segundo Momenté et al. (2003), o ponto de partida quando se pretende explorar economicamente uma espécie selvagem é o estudo de suas formas de propagação, verificando se elas apresentam viabilidade para o estabelecimento de um sistema produtivo exequível. A propagação natural no gênero Hyptis se dá por sementes, porém, a produção comercial de mudas por via sexuada tem sido limitada em virtude da dormência em suas sementes (Maia et al. 2008), da sazonalidade na sua produção e da redução rápida de sua viabilidade. Além disso, a propagação sexual para espécies medicinais não tem sido uma prática recomendada em virtude da elevada taxa de variação genética nas populações obtidas. Neste contexto, o cultivo in vitro torna-se uma importante ferramenta, pois permite a propagação rápida e em larga escala, garantindo o suprimento de material propagativo com elevada qualidade genética e sanitária (Grattapaglia \& Machado 1998). Nesse tipo de propagação, a embriogênese somática indireta tem sido preconizada como uma via adequada para a multiplicação in vitro, pois possibilita elevada taxa de multiplicação. Entretanto, a obtenção de calos friáveis, fase preliminar para obter os embriões somáticos, representa uma etapa crucial a ser ajustada.

O calo é um aglomerado de células e tecidos formado 
pela intensa divisão das células do explante. $\mathrm{O}$ tipo de calo formado em um determinado genótipo, seu grau de diferenciação celular e o seu potencial embriogênico dependem, sobretudo, do tipo de explante e do meio de cultura utilizado. A utilização de aditivos orgânicos no meio de cultura tem sido uma das alternativas para a indução de calos com elevada friabilidade (Landa et al. 2000).

A caracterização morfológica e bioquímica dos calos pode evidenciar as mudanças que ocorrem nas diferentes fases do seu crescimento, fornecendo dados importantes relacionados ao processo morfogenético in vitro de tecidos vegetais. Esses estudos podem auxiliar ainda na identificação de fatores que desencadeiam mudanças fisiológicas nos explantes, como a aquisição da friabilidade ou o desenvolvimento de embriões somáticos. Assim, o presente trabalho teve como objetivo induzir a formação de calos em segmentos foliares de H. leucocephala e avaliar o efeito de diferentes aditivos orgânicos sobre a estrutura dos calos por meio de parâmetros morfológicos (coloração, textura e presença de embriões somáticos na superfície dos calos) e bioquímicos (proteínas totais, aminoácidos livres, açúcares totais e açúcares redutores).

\section{Material e Métodos}

Para a indução de calos de Hyptis leucocephala, foram utilizados como explantes segmentos foliares provenientes de plântulas pré-estabelecidas in vitro. As culturas primárias foram obtidas a partir de sementes de plantas mantidas na coleção de plantas aromáticas do Horto Florestal da Universidade Estadual de Feira de Santana (UEFS) e identificadas no herbário desta Universidade (material-testemunho: HUEFS 131323).

Os explantes foram inoculados em tubos de ensaio contendo $8 \mathrm{~mL}$ de meio de cultura WPM (Wood Plant Medium) (Lloyd \& McCown 1980), suplementado com 3\% de sacarose e diferentes concentrações $(0,0 ; 4,44 ; 8,88$ e $17,76 \mu \mathrm{M})$ de 6-benzilaminopurina (BAP) combinadas a diferentes concentrações $(0,0 ; 5,37 ; 10,74$ e $21,48 \mu \mathrm{M})$ de ácido naftalenoacético (ANA). O meio de cultura foi solidificado com $0,7 \%$ de ágar e o $\mathrm{pH}$ do meio foi corrigido para 5,7 $\pm 0,1$ antes da autoclavagem. Após inoculação os tubos foram mantidos no escuro, em sala de crescimento, à temperatura de $25 \pm 3^{\circ} \mathrm{C}$ por um período de 60 dias. Decorrido esse período, avaliou-se a porcentagem de formação de calos com base no número de explantes com calos, massa fresca e seca dos calos, utilizando estufa de circulação forçada de ar a $40^{\circ} \mathrm{C}$ por $72 \mathrm{~h}$ e pesagem em balança de precisão, e a textura dos calos, mensurando-se manualmente a resistência dos calos à desagregação após pressão exercida com uma pinça, atribuindo-se a designação de compactos aos que não sofreram desagregação e friáveis aos que sofreram desagregação. $\mathrm{O}$ delineamento estatístico foi o inteiramente casualizado, com cinco repetições por tratamento, sendo cada repetição composta por quatro tubos com um explante em cada tubo.

Mediante os resultados obtidos no experimento anterior, um novo experimento foi conduzido, objetivando a obtenção de calos friáveis. Os segmentos foliares foram inoculados em tubos de ensaio contendo $8 \mathrm{~mL}$ de meio de cultura WPM suplementado com $3 \%$ de sacarose e solidificado com $0,7 \%$ de ágar. O meio foi suplementado ainda com 10,21 $\mu \mathrm{M}$ de BAP e 10,74 $\mu \mathrm{M}$ de ANA, considerando a análise de regressão dos resultados obtidos no primeiro experimento. Nesse experimento, avaliou-se o efeito de diferentes aditivos orgânicos, isolados e combinados, sendo: (T1) água de coco (10\%), (T2) extrato de malte $\left(0,2 \mathrm{~g} \mathrm{~L}^{-1}\right)$ [atentar para sobrescritos], (T3) extrato de levedura $\left(2,5 \mathrm{~g} \mathrm{~L}^{-1}\right)$ e (T4) água de coco $(10 \%)+$ extrato de malte $\left(0,2 \mathrm{~g} \mathrm{~L}^{-1}\right)+$ extrato de levedura $\left(2,5 \mathrm{~g} \mathrm{~L}^{-1}\right)$. Como controle, utilizou-se o meio sem a adição desses compostos. Cada tratamento consistiu de 10 repetições, cada uma com 10 tubos com um explante em cada tubo. Decorridos 60 dias, uma parte dos calos foi utilizada para a caracterização morfológica por análise visual e por microscopia eletrônica de varredura (MEV) e a outra parte foi utilizada para análise bioquímica.

Para análise bioquímica, foi obtido extrato aquoso, conforme metodologia descrita por Nogueira et al. (2008). Os calos foram homogeneizados em graal e, para cada grama de calo, foram adicionados $4 \mathrm{~mL}$ de água destilada. As amostras permaneceram a $40^{\circ} \mathrm{C}$ em banho-maria por 30 min, e foram centrifugadas a $4.800 \mathrm{xg}$ por $30 \mathrm{~min}$ a $25^{\circ} \mathrm{C}$. O sobrenadante foi recolhido e armazenado sob refrigeração para posterior análise. A quantificação do teor de açúcares solúveis totais (AST) foi realizada por refratometria. A quantificação dos açúcares redutores (AR) foi determinada pelo método do DNS (Miller 1959), utilizando glicose como padrão. A quantificação da proteína bruta (PB) e dos aminoácidos livres (AL) foi realizada a partir do método descrito por Lowry et al. (1951), utilizando-se soro de albumina bovina (BSA) como padrão. Para obtenção dos aminoácidos totais livres, foi realizada a precipitação das proteínas com o ácido tricloroacético a $25 \%$, deixando apenas os aminoácidos livres e pequenos peptídeos em solução. Para todas as análises bioquímicas, foram utilizadas três repetições em cada tratamento, com 20 tubos por repetição, avaliando-se estatisticamente os resultados mediante a análise de variância e comparando-se as médias pelo teste de Scott-Knott a 5\% de probabilidade de erro.

Para a análise da superfície via microscopia eletrônica de varredura (MEV), foram coletadas três amostras representativas dos calos obtidos em cada tratamento. Os calos foram imersos em solução fixadora glutaraldeído e desidratados em concentrações crescentes de acetona $(30 \%$, $70 \%, 80 \%, 90 \%, 95 \%$ e $100 \%)$ por 5 min em cada concentração, repetindo-se o processo por três vezes. Após a desidratação as amostras foram levadas para o aparelho de ponto crítico (CPD 030) para a secagem durante $30 \mathrm{~min}$, e então, montada em stubs para metalização com ouro no metalizador SCD 050 durante $60 \mathrm{~min}$. Finalmente, a observação das amostras foi realizada em Microscópio Eletrônico de Varredura LEO 1430 VP - Carl Zeiss do Brasil. 


\section{Resultados}

A análise de variância indicou efeitos significativos do BAP e do ANA, bem como da interação entre os mesmos, sobre a indução de calos de Hyptis leucocephala. Verificouse uma elevada porcentagem de formação de calos, com mais $60 \%$ de indução nos meios de cultura suplementados com ANA e mais de $80 \%$ de indução nos meios de cultura suplementados com concentrações superiores a $8,88 \mu \mathrm{M}$ de BAP na presença de ANA (Tabela 1). Entretanto, em todos os tratamentos, os calos obtidos foram compactos e indiferenciados. A análise de regressão para massa seca dos calos demonstrou que o modelo matemático mais representativo foi o quadrático, observando-se que a maior massa seca $(97,6 \mathrm{mg})$ pode ser obtida na presença de 10,21 $\mu \mathrm{M}$ de BAP combinado com $10,74 \mu \mathrm{M}$ de ANA.

A adição de água de coco, extrato de malte e extrato de levedura, isoladamente e combinados, não foram efetivos na indução de calos friáveis nesta espécie. Entretanto, a presença desses compostos modificou a capacidade morfogênica dos tecidos, induzindo a formação de raízes. No tratamento sem adição de compostos orgânicos, os calos apresentaram coloração esbranquiçada, textura compacta e uma pequena diferenciação de raízes. No tratamento com adição de água de coco, obteve-se calos com coloração amarelo-amarronzada, textura compacta e grande diferenciação de raízes. No tratamento contendo extrato de malte, obteve-se calos com coloração esbranquiçada, textura compacta, diferenciação em raízes e baixo crescimento. No tratamento contendo extrato de levedura, os calos obtidos apresentaram coloração escurecida e textura compacta, sem diferenciação de raízes. No meio suplementado simultaneamente com água de coco, extrato de levedura e extrato de malte, os calos apresentaram coloração amarelo-amarronzada e textura compacta, sem diferenciação de raízes.

A análise da superfície dos calos de H. leucocephala através da MEV demonstrou a ocorrência de estruturas granulares, compactas e não embriogênicas em calos induzidos em meio sem aditivos orgânicos e em meio com água de coco (Figura 1A-B). Nos calos obtidos em meio de cultura com adição de extrato de levedura e adição simultânea de água de coco, extrato de malte e extrato de levedura também verificou-se a ocorrência de massa celular compacta (Figura 1C e 1E), porém as células estavam arranjadas mais frouxamente, intercaladas por protuberâncias com abertura na extremidade, o que pode representar a fase inicial da embriogênese somática; contudo, não foram identificadas estruturas embriogênicas típicas. Verificou-se ainda, nos calos obtidos em meio de cultura suplementado com extrato de malte (Figura 1D), a ocorrência de massas celulares organogênicas e intensa diferenciação de raízes na superfície do calo.

A suplementação do meio de cultura com aditivos orgânicos promoveu uma considerável redução no teor de açúcares solúveis totais (AST), açúcares redutores (AR), proteína bruta (PB) e aminoácidos livres (AL) (Tabela 2). A suplementação do meio de cultura com água de coco e desta combinada com extrato de malte ou extrato de levedura, promoveu as maiores reduções nos teores de AST, enquanto que a suplementação do meio de cultura com extrato de levedura, e deste combinado com água de coco ou extrato de malte promoveu a maior redução no teor de $\mathrm{AL}$ (Tabela 2).

\section{Discussão}

Os resultados obtidos em relação à indução e à

Tabela 1. Percentual de explantes com calos (calogênese), massa fresca, massa seca e textura dos calos de Hyptis leucocephala cultivados em meio WPM suplementado com diferentes concentrações de 6-benzilaminopurina (BAP) e ácido naftalenoacético (ANA). Médias seguidas de mesma letra na coluna não diferem entre si significativamente a $5 \%$ de probabilidade de erro pelo teste de Scott-Knott.

\begin{tabular}{cccccc}
\hline $\begin{array}{c}\text { BAP } \\
(\mu \mathrm{M})\end{array}$ & $\begin{array}{c}\text { ANA } \\
(\mu \mathrm{M})\end{array}$ & $\begin{array}{c}\text { Calogênese } \\
(\%)\end{array}$ & $\begin{array}{c}\text { Massa fresca } \\
(\mathrm{mg})\end{array}$ & $\begin{array}{c}\text { Massa seca } \\
(\mathrm{mg})\end{array}$ & Textura \\
\hline 0,0 & 0,0 & $0^{\mathrm{d}}$ & $0^{\mathrm{c}}$ & $0^{\mathrm{e}}$ & compacta \\
0,0 & 5,37 & $65,2^{\mathrm{b}}$ & $610,2^{\mathrm{b}}$ & $47,0^{\mathrm{d}}$ & compacta \\
0,0 & 10,74 & $70,4^{\mathrm{b}}$ & $805,1^{\mathrm{b}}$ & $65,4^{\mathrm{c}}$ & compacta \\
0,0 & 21,48 & $54,1^{\mathrm{b}}$ & $915,7^{\mathrm{b}}$ & $79,5^{\mathrm{b}}$ & compacta \\
4,44 & 0,0 & $18,7^{\mathrm{c}}$ & $398,3^{\mathrm{b}}$ & $31,2^{\mathrm{d}}$ & compacta \\
4,44 & 5,37 & $31,0^{\mathrm{c}}$ & $785,0^{\mathrm{b}}$ & $66,8^{\mathrm{c}}$ & compacta \\
4,44 & 10,74 & $74,2^{\mathrm{b}}$ & $965,8^{\mathrm{b}}$ & $72,5^{\mathrm{b}}$ & compacta \\
4,44 & 21,48 & $71,2^{\mathrm{b}}$ & $925,4^{\mathrm{b}}$ & $77,5^{\mathrm{b}}$ & compacta \\
8,88 & 0,0 & $21,5^{\mathrm{c}}$ & $575,3^{\mathrm{b}}$ & $41,5^{\mathrm{d}}$ & compacta \\
8,88 & 5,37 & $65,0^{\mathrm{b}}$ & $836,1^{\mathrm{b}}$ & $72,1^{\mathrm{b}}$ & compacta \\
8,88 & 10,74 & $95,0^{\mathrm{a}}$ & $1114,3^{\mathrm{a}}$ & $94,6^{\mathrm{a}}$ & compacta \\
8,88 & 21,48 & $89,1^{\mathrm{a}}$ & $1240,1^{\mathrm{a}}$ & $103,4^{\mathrm{a}}$ & compacta \\
17,76 & 0,0 & $34,8^{\mathrm{c}}$ & $1197,5^{\mathrm{a}}$ & $105,7^{\mathrm{a}}$ & compacta \\
17,76 & 5,37 & $94,8^{\mathrm{a}}$ & $1169,0^{\mathrm{a}}$ & $97,2^{\mathrm{a}}$ & compacta \\
17,76 & 10,74 & $85,0^{\mathrm{a}}$ & $1312,1^{\mathrm{a}}$ & $109,0^{\mathrm{a}}$ & compacta \\
17,76 & 21,48 & $95,3^{\mathrm{a}}$ & $1126,1^{\mathrm{a}}$ & $91,4^{\mathrm{a}}$ & compacta \\
\hline
\end{tabular}



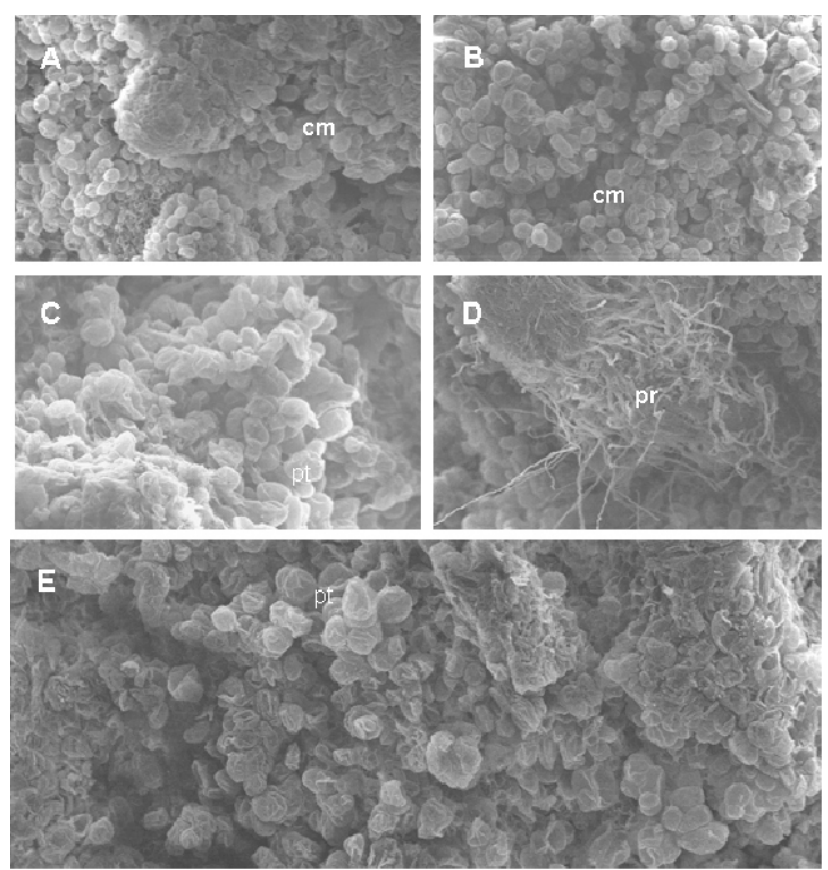

Figura 1. Eletromicrografia de varredura de calos obtidos a partir de segmentos foliares de $H$. leucocephala em meio WPM na presença de aditivos orgânicos: A- sem suplementação de aditivos orgânicos; B- adição de água de coco (10\%); $\mathbf{C}$ - adição de extrato de levedura $\left(2,5 \mathrm{~g} \mathrm{~L}^{-1}\right)$; Dadição de extrato de malte $\left(0,2 \mathrm{~g} \mathrm{~L}{ }^{-1}\right)$; E- adição de água de coco $(10 \%)+$ extrato de malte $\left(0,2 \mathrm{~g} \mathrm{~L}^{-1}\right)+$ extrato de levedura $\left(2,5 \mathrm{~g} \mathrm{~L}^{-1}\right)$. A e B: Massa granular com células meristemáticas $(\mathrm{cm})$. C e E: Massa granular com células com características embriogênicas e protuberância semelhante a um coleóptilo (pt). D: Massa granular com diferenciação de raízes na superfície e primórdios de raízes ( $\mathrm{pr}$ ).

morfologia dos calos são bastante variáveis em função da espécie, da fonte de explante e do meio de cultura utilizado. Cerqueira (1999) observou $100 \%$ da área do explante coberta por calo em segmentos foliares de erva-de-touro (Tridax procumbens L.) utilizando $2,0 \mu \mathrm{M}$ de ANA combinado com 2,0 $\mu \mathrm{M}$ de BAP. Já Landa et al. (2000) obteve o maior percentual de indução de calo em explante foliar de pequizeiro (Caryocar brasiliense Cambess.) utilizando $10,74 \mu \mathrm{M}$ de ANA e 2,22 $\mu \mathrm{M}$ de BAP, enquanto Lima et al. (2008), trabalhando com sangra-d'água (Croton urucurana Baill.), verificaram que o uso de BAP isoladamente e a combinação de ANA e BAP não promoveram calogênese em segmentos foliares.

Em relação à textura dos calos, diferentemente dos resultados obtidos neste trabalho, Santos et al. (2008) obtiveram calos friáveis em Syngonanthus mucugensis Giul., utilizando variadas concentrações de BAP. Para aqueles autores, a friabilidade seria uma característica importante para obtenção de embriões somáticos, sendo bastante correlaciona à espécie e ao tipo de explante.

Alguns trabalhos têm correlacionado a friabilidade dos calos à adição de compostos orgânicos no meio de cultura. Rey \& Mroginski (1996), trabalhando com Aeschynomene spp., observaram que os calos obtidos em meio de cultura sem a presença de aditivos orgânicos eram duros e de coloração variando entre o branco, marrom e acinzentado, apresentando raízes, enquanto que os calos obtidos em meio suplementado com aditivos orgânicos eram friáveis e de coloração clara. Por outro lado, Figueiredo et al. (2007), trabalhando com dois acessos de maracujazeiro (Passiflora edulis f. flavicarpa Deg.) verificaram a formação de calos com coloração amarelo-esverdeada e textura friável mesmo sem a adição de compostos orgânicos, o que demonstra que a friabilidade está relacionada à espécie. Landa et al. (2000), avaliando o efeito da adição de aditivos orgânicos na indução in vitro de calos em explantes foliares de pequizeiro (Caryocar brasiliense), verificaram que calos obtidos em meio suplementado com 5,37 $\mu \mathrm{M}$ ANA $+1,11$ $\mu \mathrm{MBAP}+50 \mathrm{mLL}^{-1}$ de água de coco, ou em meio acrescido de $5,37 \mu \mathrm{M}$ ANA $+1,11 \mu \mathrm{MBAP}+250 \mathrm{mg} \mathrm{L}^{-1}$ de extrato de levedura, apresentaram aspecto oxidado e/ou necrosado. Verificaram ainda que o uso do extrato de malte no meio de cultura proporcionou a formação de calos com melhor aspecto visual, induzindo à formação de brotações e raízes em setores do calo. Entretanto, a maior percentagem de crescimento de calos foi obtida na ausência desse aditivo, corroborando os resultados obtidos no presente trabalho.

O tamanho e o formato das células dos calos têm sido correlacionados à capacidade embriogênica desses calos. Segundo Fernando et al. (2001), trabalhando com embriogênese somática de Carica papaya L., células grandes, com forma alongada, e altamente vacuolizadas, são características de calos não embriogênicos, enquanto células pequenas, esféricas e com citoplasma denso, constituindo arranjos meristemáticos compactos, são características de calos com competência embriogênica.

Diversos trabalhos têm correlacionado a composição química dos calos ao estádio de desenvolvimento dos mesmos. Contudo, poucos trabalhos têm buscado relacionar esses parâmetros à textura dos calos. Segundo Cangahuala Inocente et al. (2009), os níveis de açúcares

Tabela 2. Teores de açúcares solúveis totais (AST), açúcares redutores (AR), proteína bruta (PB) e aminoácidos livres (AL) na massa fresca (MF) de calos de Hyptis leucocephala obtidos em meio de cultura WPM sem suplementação de aditivos orgânicos e suplementados com água de coco (10\%), extrato de malte $\left(0,2 \mathrm{~g} \mathrm{~L}^{-1}\right)$, extrato de levedura $\left(2,5 \mathrm{~g} \mathrm{~L}^{-1}\right)$ e água de coco, extrato de malte e extrato de levedura combinados. Médias seguidas de mesma letra na coluna não diferem entre si significativamente a $5 \%$ de probabilidade de erro pelo teste de Scott-Knott.

\begin{tabular}{lcccc}
\hline Tratamento & $\begin{array}{c}\text { AST } \\
(\mathrm{mg} / \mathrm{g} \mathrm{de} \mathrm{MF})\end{array}$ & $\begin{array}{c}\text { AR } \\
(\mathrm{mg} / \mathrm{g} \mathrm{de} \mathrm{MF})\end{array}$ & $\begin{array}{c}\text { PB } \\
(\mathrm{mg} / \mathrm{g} \mathrm{de} \mathrm{MF})\end{array}$ & $\begin{array}{c}\text { AL } \\
(\mathrm{mg} / \mathrm{g} \mathrm{de} \mathrm{MF})\end{array}$ \\
\hline Sem aditivos & $50,0^{\mathrm{a}}$ & $7,73^{\mathrm{a}}$ & $5,59^{\mathrm{a}}$ & $6,62^{\mathrm{a}}$ \\
Água de coco (AC) $^{\mathrm{a}}$ & $16,6^{\mathrm{c}}$ & $4,42^{\mathrm{b}}$ & $2,30^{\mathrm{b}}$ & $6,17^{\mathrm{a}}$ \\
Extrato de malte (EM) & $25,0^{\mathrm{b}}$ & $4,86^{\mathrm{b}}$ & $1,96^{\mathrm{b}}$ & $4,53^{\mathrm{b}}$ \\
Extrato de levedura (EL) & $25,0^{\mathrm{b}}$ & $4,87^{\mathrm{b}}$ & $2,30^{\mathrm{b}}$ & $2,03^{\mathrm{c}}$ \\
AC + EM + EL & $16,6^{\mathrm{c}}$ & $5,36^{\mathrm{b}}$ & $2,28^{\mathrm{b}}$ & $1,88^{\mathrm{c}}$ \\
\hline
\end{tabular}

Sitientibus série Ciências Biológicas 12(1): 151-156. 2012. 
totais em embriões somáticos de Acca sellowiana (O.Berg) Burret variaram de acordo com seus estádios de desenvolvimento, tendo diminuído quando o meio de cultura foi suplementado com alguma fonte de carbono. Paiva Neto (1996) também verificou uma considerável redução nos teores de açúcares redutores em calos obtidos a partir de segmentos foliares de moreira (Chlorophora tinctoria L.) com o avanço dos estádios de desenvolvimento dos mesmos. Para Serra et al. (2000), a reduzida absorção de sacarose presente no meio de cultura justifica a redução no teor desses açúcares em calos in vitro, decorrente da redução na taxa de síntese de compostos orgânicos, considerando que muitos já estão presentes nos aditivos orgânicos. Já Mezzetti et al. (1991) atribuíram a redução no teor de açúcares à acentuada utilização desses compostos para produção de energia a ser utilizada na fase exponencial de crescimento do calo. Para aqueles autores, a suplementação com aditivos orgânicos estimula a taxa de crescimento dos calos, induzindo a maior utilização de açúcares redutores.

Cangahuala Inocente et al. (2009) relacionaram os baixos teores de proteínas nos calos ao elevado consumo das mesmas para rediferenciação de células somáticas. Logo, sugere-se que os resultados obtidos aqui para $H$. leucocephala decorreram do maior consumo de proteínas pelas células para a diferenciação de raízes e estruturas pré- embriogênicas observadas nos calos obtidos na presença de extrato de malte e de levedura, respectivamente (Figura $1 C-E)$. Já Nogueira et al. (2008) verificaram uma elevada concentração de aminoácidos livres em calos de muricipequeno (Byrsonima intermedia A.Juss.) quando o meio foi suplementado com aditivos orgânicos. Para eles, a elevada produção de aminoácidos livres encontrados nos calos daquela espécie poderia estar relacionada à assimilação da glicina presente no meio de cultura. Esses mesmos autores indicaram um declínio dos teores de aminoácidos ao longo do tempo de cultivo, o que pode ser atribuído ao consumo dos aminoácidos endógenos para a síntese de proteínas exigidas no crescimento celular.

\section{Conclusões}

A utilização de BAP e ANA pode induzir calos compactos em segmentos foliares de Hyptis leucocephala. A suplementação do meio de cultura com água de coco, extrato de malte e extrato de levedura não induz a formação de calos friáveis em segmentos foliares dessa espécie. Finalmente, a suplementação do meio de cultura com compostos orgânicos induz a redução dos teores de açúcares solúveis totais, açúcares redutores e proteína bruta nos calos.

\section{REFERÊNCIAS}

Cangahuala Inocente, G.C.; Steiner, N.; Maldonado, S.B. \& Guerra, M.P. 2009. Patterns of protein and carbohydrate accumulation during somatic embryogenesis of Acca sellowiana. Pesquisa Agropecuária Brasileira 44(3): 217-224.

Cerqueira, E.S. 1999. Propagação e Calogênese in vitro em Erva-de-Touro (Tridax procumbens L.), uma planta medicinal. Dissertação (Mestrado em Fisiologia Vegetal) Universidade Federal de Lavras.

Falcão, D.Q. \& Menezes, F.S. 2003. Revisão etnofarmacológica, farmacológica e química do gênero Hyptis. Revista Brasileira de Farmacognosia 84(3): 69-74.

Fernando, J.A.; Melo, M.; Soares, M.K.M. \& Appezzato-daGlória, B. 2001. Anatomy of somatic embryogenesis in Carica papaya L. Brazilian Archives of Biology and Techinology 44(3): 247-255.

Figueiredo, M.A.; Paiva, R.; Souza, A.C.; Porto, J.M.P.; Nogueira, G.F. \& Soares, F.P. 2007. Indução in vitro de calos em duas espécies de maracujazeiro nativo. Revista Brasileira de Biociências 5(supl. 2): 288-290.

Grattapaglia, D. \& Machado, M.A. 1998. Micropropagação. In: A.C. Torres, L.S. Caldas \& J.A. Buso (eds), Cultura de Tecidos e Transformação Genética de Plantas. Vol. 1. Embrapa-SPI/Embrapa CNPH, Brasília, p. 183-260.

Judd, W.S..; Campbell, C.S.; Kellogg, E.A. \& Stevens, P.F. 1999. Plant Systematics: a phylogenetic approach. Sinauer Associates, Sunderland.

Landa, F.S.L.; Paiva, R.; Paiva, P.D.O. \& Bueno, J.S.S.F. 2000. Indução in vitro de calos em explantes foliares de pequizeiro (Caryocar brasiliense Camb.). Ciência e Agrotecnologia 24(Edição Especial): 56-63.

Lima, E.C.; Paiva, R.; Nogueira, R.C.; Soares, F.P.; Emrich,
E.B. \& Silva, A.A.N. 2008. Indução de calos em segmentos foliares de sangra d'água (Croton urucurana Baill.). Ciência e Agrotecnologia 32(1): 17-22.

Lloyd, G. \& Mccown, B. 1980. Use of microculture for production and improvement of Rhododendron spp. HortScience 15: 416-420.

Lowry, O.H.; Rosebrough, N.J. \& Farr, A.L. 1951. Protein measurement with the Folin phenol reagent. Journal of Biological Chemistry 193: 265-275.

Lucchese, A.M.; Oliveira, L.S.; Rodrigues, O.S.; Moreira, J.S.; Zaim, C.Y.H.; Zaim, M.H.; Queiroz, L.P.; Giulietti, A.M.; Uetanabaro, A.P.T. \& Conceicao, T.A. 2005. Óleos essenciais do gênero Hyptis da região do Semi-árido da Bahia. In Anais do III Simpósio Brasileiro de Óleos Essencias, Campinas. Instituto Agronômico de Campinas, Campinas.

Maia, S.S.S.; Pinto, J.E.B.P.; Oliveira, J.A.; Silva, F.N. \& Santos, F.M. 2008. Germinação de sementes de Hyptis suaveolens (L.) Poit. (Lamiaceae) em função da luz e da temperatura. Caatinga 21(4): 212-218.

Mezzetti, B.; Conte, L.S. \& Rosati, P. 1991. Actinidia deliciosa in vitro: II. Growth and exogenous carbohydrates utilization by explants. Plant Cell, Tissue and Organ Culture 26: 153-160.

Miller, G.L. 1959. Use of dinitrosalicylic acid reagent for determination of reducing sugar. Analytical Chemistry 31: 426-428.

Momenté, V.G.; Bezerra, A.M.E.; Innecco, R.; Ledo, A.S. \& Alves, M.C.S. 2003. Crescimento inicial de mudas de mentrasto "forma florífera". Ciência Agronômica 34(1): 5-10.

Nogueira, R.C.; Paiva, R.; Lima, E.C.; Soares, G.A.; Oliveira, L.M.; Santos, B.R.; Emrich, E.B. \& Castro, A.H.F. 2008. 
Curva de crescimento e análises bioquímicas de calos de murici-pequeno (Byrsonima intermedia A. Juss.). Revista Brasileira de Plantas Medicinais 10(1): 4-48.

Paiva Neto, V.B. 1996. Comportamento in vitro de Tecido Foliar e Segmento Nodal de Moreira (Chlorophora tinctoria (L.) Gaudichaud). Dissertação (Mestrado em Fisiologia Vegetal). Universidade Federal de Lavras.

Rey, H.Y. \& Mroginski, L.A. 1996. Regeneration of plants from callus tissue of Aeschynomene spp. (Leguminosae). Plant Cell, Tissue and Organ Culture 45(3): 185-190.
Santos, J.P.; Dornelles, A.L.C.; Pereira F.D. \& Oliveira L. M. 2008. Indução de calos em sempre-viva (Syngonanthus mucugensis Giulietti), utilizando diferentes tipos de explantes e concentrações de BAP. Acta Scientiarum Biological Sciences 30(2): 127-131.

Serra, A.G.P.; Paiva, R. \& Paiva, P.D.O. 2000. Análises bioquímicas de calos formados de explantes foliares de castanha-do-brasil (Bertholletia excelsa H. B. K.). Ciência e Agrotecnologia 24(4): 833-840. 